\title{
Molecular structure and vibrational analysis of 2-vinyl furan
}

\author{
Giuliani A[1], Gilbert B ${ }^{[2]}$, Kech $\mathrm{C}^{[3]}$, Hubin-Franskin M-J[1]

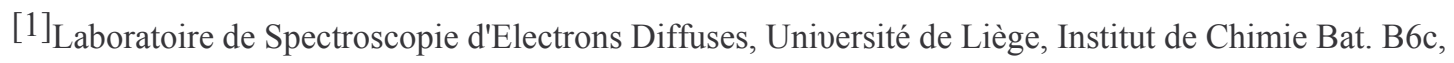 \\ B-4000 Liège, Belgium \\ [2] Chimie Analytique et Electrochimie, Institut de Chimie Bat. B6c, Université de Liège, B-4000 \\ Liège, Belgium

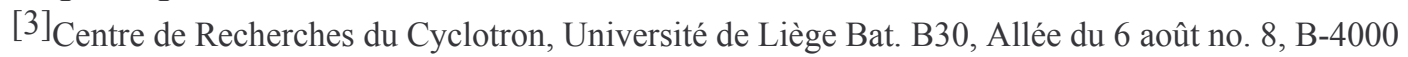 \\ Liège, Belgium
}

\begin{abstract}
Infrared and vibrational Raman spectra have been recorded in the liquid phase and interpreted using semiempirical calculations (PM3, AMI and MNDO). Molecular properties and relative conformational energies have been calculated and compared with literature data, when available. The trans conformer of the molecule seems to be the conformation of lowest energy and its computed structural parameters are reported.
\end{abstract}

\section{Introduction}

The 2-vinyl furan molecule (Fig. 1) is important as a synthetic reagent in polymer chemistry, being used to produce resins and polymers [1]. It belongs to a group of monomers, incorporating the furan moiety, that may be produced from biomass. This family thus represents a possible alternative to petroleum-based monomers [2],

Despite its interest, little work has been reported on the molecular properties of 2-vinyl fu-ran. A single microwave investigation [3] has been published but, as far as we are aware, no information is available on its vibrational spectrum.

We have been concerned with the spectroscopic properties of furan derivatives [4-7]. Pertinent to this is the investigation of the Infrared (IR) and vibrational Raman spectra of the 2-vinyl furan reported here.

\section{Experimental methods}

The Fourier transform infrared (FT-IR) spectrum was recorded on a Bruker IFS66 machine using KBr windows in the $3500-400 \mathrm{~cm}^{-1}$ region. The accuracy on the FR-IR measurements is estimated to be $\pm 5 \mathrm{~cm}^{-1}$. Vibrational Raman spectra were recorded on a Jobin Yvon Lab Ram spectrometer using an Argon ion laser $(514.5 \mathrm{~nm})$. Samples were placed in glass cuvette. The Stokes' region was recorded from 3300 to the notch filter cut off at $\sim 100 \mathrm{~cm}^{-1}$. The accuracy on the Raman spectra is estimated to be $\pm 4 \mathrm{~cm}^{-1}$.

The sample was prepared according to the method described by Fabian and Tchelitcheff [8] and modified by Schmidt and Werner [9] Briefly, thermal decarboxylation, catalyzed by copper(I) oxide, of furyl acrylic acid in quinoline under argon produced 2-vinyl furan. The crude material was dried over magnesium sulfate and rectified on a $40 \mathrm{~cm}$ Vigreux column. The purity, as determined by GC-MS, was better than 99\%. One ppm butylated hydroxytoluene (BHT) was added as stabilizing agent. Overall yield was $65 \%$.

Boiling point $98-99^{\circ} \mathrm{C}$ (Litt. 99-100 ${ }^{\circ} \mathrm{C}$ [8], 98-99 ${ }^{\circ} \mathrm{C}[10],{ }^{1} \mathrm{H}-\mathrm{NMR}\left(250 \mathrm{MHz}\right.$ in $\left.\mathrm{CDCl}_{3}, \mathrm{RT}\right): \delta$ $=5.17 \mathrm{ppm}\left[\mathrm{dd}, 1 \mathrm{H},{ }^{2} J_{\beta y}=1.20 \mathrm{~Hz},{ }^{3} \mathrm{~J}_{\alpha \gamma}=11.34 \mathrm{~Hz}, H_{\gamma}\right], \delta=5.67 \mathrm{ppm}\left[\mathrm{dd}, 1 \mathrm{H},{ }^{2} J_{\beta \gamma}=1.20 \mathrm{~Hz}\right.$, $\left.3 \mathrm{~J}_{\alpha \beta}=17.44 \mathrm{~Hz}, H_{\beta}\right], \delta=6.27 \mathrm{ppm}\left[\mathrm{d}, 1 \mathrm{H}, \mathrm{V}_{34}=3.24 \mathrm{~Hz}, \mathrm{H}_{3}\right],, \delta=6.38 \mathrm{pm}\left[\mathrm{dd}, 1 \mathrm{H},{ }^{3} \mathrm{~J}_{45}=1-78 \mathrm{~Hz}\right.$, $\left.{ }^{3} \mathrm{~J}_{34}=3.16 \mathrm{~Hz}, \mathrm{H}_{4}\right], \delta=6.51 \mathrm{ppm}\left[\mathrm{dd}, 1 \mathrm{H} .{ }^{3} \mathrm{~J}_{\alpha \gamma}=11.28 \mathrm{~Hz},{ }^{3} \mathrm{~J}_{\alpha \beta}=17.49 \mathrm{~Hz}, \mathrm{H}_{\alpha}\right], \delta=7.37 \mathrm{ppm}[\mathrm{s}$, $\left.1 \mathrm{H}, \mathrm{H}_{5}\right]$. 
<smiles>CC=Cc1oc(C)c(C)c1C</smiles><smiles>C/C(=C\Br)c1ccc(C)o1</smiles>

Fig. 1. 2-Vinyl furan molecule with atom numbering: (a) trans conformer; (b) cis conformer.

\section{Theoretical methods}

The semiempirical calculations were performed with the software package MOPAC 2000 [11]. All calculations were made at the RHF SCF level of theory with configuration interactions (SDCI) and using the MNDO, [12] AM1 [13] and PM3[14] semiempirical methods. Those last are based on the neglect of diatomic differential overlap (NDDO) approximation. They contain sets of parameters, which come either from experimental data (not optimized) or are optimized. In contrast with the other, the PM3 method uses only optimized parameters. In addition, AM1 and PM3 have a modified expression for the core-core repulsion integral compared to MNDO.

Table 1 Relative conformational energies for different conformations of 2-vinyl furan

\begin{tabular}{|c|c|c|c|}
\hline & $\begin{array}{l}E \\
(\mathrm{~kJ} / \mathrm{mol})^{11} \\
\text { trans }\end{array}$ & cis & $90^{\circ \mathrm{b}}$ \\
\hline $\mathrm{PM}_{3} \mathrm{C}$ & 3.26 & 0.00 & 14.74 \\
\hline $\mathrm{AM} 1 \mathrm{C}$ & 0.00 & 0.10 & 16.15 \\
\hline $\mathrm{MNDO}^{\mathrm{c}}$ & 0.00 & 0.88 & 6.42 \\
\hline STO- $3 \mathrm{G}^{\mathrm{d}}$ & 0.00 & 2.58 & 25.70 \\
\hline $\mathrm{INDO}^{\mathrm{d}}$ & 0.65 & 0.00 & 13.55 \\
\hline $\begin{array}{l}\mathrm{CNDO} / 2 \\
\mathrm{~d}\end{array}$ & 0.00 & 0.72 & 12.20 \\
\hline STO- $3 \mathrm{G}^{\mathrm{e}}$ & 0.00 & 3.04 & 24. \\
\hline
\end{tabular}

${ }^{a}$ Conformational energies are given relatively to the most stable conformation. ${ }^{b}$ Conformation for which the dihedral angle $C_{3} C_{2} C_{6} C_{7}$ is $90^{\circ} .{ }^{c}$ This work. ${ }_{\text {Ref. [17]. }}{ }_{\text {Ref. [18]. }}$

This explains the different numerical values for the relative conformational energies reported in Table 1. Although the PM3 method has been found to be usually in better agreement with experiment than AMI and MNDO [15], this is not always the case. Therefore comparison of the three methods turns out to be useful and agreements in the outcome of several methods are believed to indicate more secure results. The equilibrium structures were fully optimized using the eigenvector following routine (EF) [16]. 


\section{Results and discussion}

\subsection{Equilibrium structure - conformational energies - molecular properties}

The equilibrium structure of the molecule has been theoretically investigated by others. Parr et al. [17] calculated the relative energies of cis, trans and $90^{\circ}$ conformers of 2-vinyl furan by both ab inito (STO$3 \mathrm{G}$ ) and semiempirical methods (INDO, CNDO/2 and MINDO/3). Their calculations give conflicting results; the STO-3G method finds the trans conformer to be the most stable, whereas the semiempirical methods favour the cis form. INDO and STO-3G methods concur in predicting only small energy differences between cis and trans conformations.

Table 2 Calculated molecular properties for cis and trans 2-vinyl furan and comparison with experimental data

Method Property

$\mu_{\text {total }}(\mathrm{D})$

Microwave $0.69(7)^{\mathrm{e}}$

$\begin{array}{lll} & \text { trans } & \text { cis } \\ \mathrm{PM}^{\mathrm{b}} & 0.27 & 0.36 \\ \mathrm{AM}^{\mathrm{b}} & 0.45 & 0.61 \\ \mathrm{MNDO}^{\mathrm{b}} & 0.45 & \mathbf{0 . 6 3} \\ \mathrm{STO}^{\mathrm{b}} \mathrm{G}^{\mathrm{c}} & 0.33 & \mathbf{0 . 3 9} \\ \mathrm{INDO}^{\mathrm{c}} & 0.82 & 0.64 \\ \mathrm{CNDO} / 2^{\mathrm{c}} & 0.88 & \mathbf{0 . 6 9}\end{array}$

STO-3Gd $\quad 0.45$

Rotational constant $(\mathrm{MHz})$

Microwave $A$

$B$

0.36

0.61

63

.39

0.69

\begin{tabular}{|c|c|c|c|c|c|c|}
\hline & $7828.385(4)^{\mathrm{e}}$ & & $2112.551(4)^{\mathrm{e}}$ & & 1667.170 & \\
\hline & trans & & & cis & & \\
\hline & $A$ & $B$ & $C$ & $A$ & $B$ & $\mathrm{C}$ \\
\hline$M 3^{b}$ & 7639.822 & 2084.487 & 1637.647 & 7681.044 & 2041.557 & 1612.854 \\
\hline $\mathrm{Ml}^{\mathrm{b}}$ & 7550.184 & 2086.856 & 1634.948 & 7635.895 & 2018.383 & 1596.395 \\
\hline $\mathrm{DO}^{\mathrm{b}}$ & 7707.905 & 2018.053 & 1599.333 & 7726.4022 & 1979.680 & 1575.919 \\
\hline
\end{tabular}

Moments of inertia $\left(10^{-40} \mathrm{~g} \mathrm{~cm}^{-2}\right)$

Microwave $I_{A} \quad I_{B} \quad I_{C}$

$\begin{array}{lll}107.199258(5)^{\mathrm{e}} & 397.243590(7)^{*} & 504.27363(9)\end{array}$

\begin{tabular}{llllll} 
trans & cis \\
\hline$I_{A}$ & $I_{B}$ & $l c$ & $I_{A}$ & $I_{B}$ & $l c$
\end{tabular}

$\begin{array}{lllllll}\text { PM3 }^{\mathrm{b}} & 109.8460 & 402.5941 & 512.4400 & 109.2562 & 411.0626 & 520.3183 \\ \text { AM1 }^{\mathrm{b}} & 111.1498 & 402.1379 & 513.2877 & 109.9022 & 415.7791 & 525.6812 \\ \text { MNDO }^{\mathrm{b}} & 108.8756 & 415.8459 & 524.7215 & 108.6149 & 423.9054 & 532.5200\end{array}$

$a_{\text {Ref. [3]. }}$

$b_{\text {This work. }}$

${ }^{c}$ Ref. [17].

$d_{\text {Ref. [18]. }}$

$\boldsymbol{e}_{R M S}$ values given in parenthesis refer to the last digit. For example 0.69(7) is equivalent to 0.69 \pm 0.007 . 
John and Radom [18] subsequently reconsidered the equilibrium structure of the molecule. They used $\mathrm{ab}$ initio MO calculations with the minimal STO-3G basis set, finding the trans conformation to be the most stable. Rotational barriers computed by Parr et al. [17] and John and Radom [18] agree well (Table 1).

We are aware of a single microwave experiment on 2-vinyl furan [3]. From this, the authors determined the molecule to be planar. On the basis of an estimation of the dipole moment for each conformer and its projection along two axes, they concluded that the observed rotational spectrum was due to the trans conformation. Signal due to the cis form was detected but the intensity was too low for analysis. Hence, one conformer is predominant in the vapor phase [3].

We have computed formation enthalpies for the cis, trans and $90^{\circ}$ conformers. AMI and MNDO methods concur in finding the trans form as the most stable in contrast to the PM3 methods. All three procedures give small differences in energies between the two conformers. The rotational barrier, as estimated from the relative conformation energies (Table 1), ranges from $\sim 6.4$ to $16.2 \mathrm{~kJ} / \mathrm{mol}$, which is not much in disagreement with the STO-3G predictions [17,18]. From the Boltzman population, a rotational barrier of $10 \mathrm{~kJ} / \mathrm{mol}$ would result around $1 \%$ cis conformer. This is consistent with the low intensity microwave spectrum for the cis form reported by Latypova et al. [3] since $10 \mathrm{~kJ} / \mathrm{mol}$ is very likely an inferior limit for the rotational barrier (Table 1).

In Table 2, computed dipole moments, rotational constants and moments of inertia are listed for cis and trans conformers and the values compared with the available literature data. From the computed dipole moments, it is not possible to choose which relates better to experimental data [3]. However, comparison of the calculated rotational constants and moments of intertia with those experimentally measured (Table 2) shows that the best agreement with experiment is obtained for the trans rotamer; the computed values of $\mathrm{I}_{C}$ are much closer to experiment than those obtained for the cis conformation.

Table 3 Molecular structure for trans 2-vinyl furan. Atom labeling is given at Fig. 1

PM3

Bond length $(A)$

$\mathrm{OC}_{5} \quad 1.374$

$\mathrm{OC}_{4} \quad 1.388$

$\mathrm{C}_{4} \mathrm{C}_{5} \quad 1.384$

$\mathrm{C}_{3} \mathrm{C}_{4} \quad 1.437$

$\mathrm{C}_{2} \mathrm{C}_{3}$

$\mathrm{C}_{2} \mathrm{C}_{6} \quad 1.443$

$\mathrm{C}_{6} \mathrm{C}_{7}$

$\mathrm{C}_{5} \mathrm{H}$

$\mathrm{C}_{4} \mathrm{H} \quad 1.086$

$\mathrm{C}_{3} \mathrm{H} \quad 1.086$

$\mathrm{C}_{6} \mathrm{H}$

$\mathrm{C}_{7} \mathrm{H}$

Angle ( $\left.{ }^{\circ}\right)$

$\mathrm{OC}_{5} \mathrm{C}_{4} \quad 110.7$

$\mathrm{OC}_{2} \mathrm{C}_{3} \quad 109.8$

$\mathrm{C}_{2} \mathrm{C}_{3} \mathrm{C}_{4} \quad 106.4$

$\mathrm{C}_{5} \mathrm{C}_{4} \mathrm{C}_{3} \quad 106.2$

$\mathrm{C}_{3} \mathrm{C}_{2} \mathrm{C}_{6} \quad 130.0$

$\mathrm{C}_{2} \mathrm{C}_{6} \mathrm{C}_{7} \quad 124.9$

$\mathrm{HC}_{5} \mathrm{C}_{4}$

$\mathrm{HC}_{4} \mathrm{C}_{3} \quad 127.5$

$\mathrm{HC}_{3} \mathrm{C}_{4} \quad 126.3$

$\mathrm{HC}_{6} \mathrm{C}_{2}$

$\mathrm{H}_{\gamma} \mathrm{C}_{7} \mathrm{C}_{6}$

$\mathrm{H}_{\beta} \mathrm{C}_{\gamma} \mathrm{C}_{6}$ 
Indeed, as the $\mathrm{I}_{\mathcal{C}}$ moment of inertia is perpendicular to the molecular plane, it is very sensitive to the relative position of the vinyl group to the cycle. In addition it has the same direction in both cis and trans vinyl furan which allows direct comparison between the two conformations. This observation adds credence to the findings of Latypova et al. [3] that the trans conformational isomer predominates in the vapor phase.

From the above considerations, we suppose that the trans conformation is the equilibrium structure and report PM3 computed structural parameters for only this one (Table 3).

\subsection{Normal vibrational modes}

The molecule possesses 33 normal vibrational modes distributed through 10a" and 23a'; the $a^{\prime \prime}$ modes are anti-symmetric and the a' ones are symmetric with respect to the molecular symmetry plane. In Table 4, the symmetric vibrations are labeled v1-v23 in order of increasing wavenumber and the antisymmetric modes, likewise, v24-v33.

Assignations of the normal vibrational modes were made by comparison with PM3, AM1 and MNDO calculations. In correlating calculated vibrational frequencies with those observed in the IR spectrum, consideration was given to absorption intensities. In most cases, calculated frequencies having large transition dipoles were identified with the more intense absorption bands in the IR spectrum. The results are gathered in Table 4.

Normal modes of energy higher than $3000 \mathrm{~cm}^{-1}$ can be described as mainly $\mathrm{CH}$ stretch vibrations. For these, all three parameterizations agree on the relative ordering of both frequencies and infrared transition dipoles. The best agreement with experiment is achieved for PM3 with an average deviation of $\sim 32 \mathrm{~cm}^{-1}$, which is of the order of $1 \%$. AMI and MNDO differ by $\sim 5 \%$ and $\sim 10 \%$, respectively, from the measured data.

Between 3150 and $991 \mathrm{~cm}^{-1}$, the average difference between theory and experiment is $\sim 25, \sim 60$ and $\sim 90 \mathrm{~cm}^{-1}$, for, respectively, PM3, AM1 and MNDO. However, for those modes whose measured frequency is above about $1000 \mathrm{~cm}^{-1}$, all computations find the same energy ordering, leading to straightforward assignments. In contrast, differences appear between the different methodologies for lower frequency vibrations. This is not surprising given the relatively small energy differences between some of the modes. In assigning the measured spectrum, we have followed the PM3 results, but assignments cannot be considered definitive for closely spaced vibrational modes.

The three vibrations of lowest frequency were detected in only the Raman spectrum. It is clear that one of these is of a' symmetry, which from the PM3 and AMI results, we assign to the $215 \mathrm{~cm}^{-1} \mathrm{band}$. Latypova et al. [3] detected two vibration-ally excited levels whose reported wavenumbers are $119 \pm 27$ and $232 \pm 20 \mathrm{~cm}^{-1}$. These values are in excellent agreement with our present data of $129 \pm 4$ and $215 \pm 4$ $\mathrm{cm}^{-1}$ for modes la" and la'. 
Table 4 Normal vibrational modes for trans 2-vinyl furan (wavenumbers are given in $\mathrm{cm}^{l}$ )

Sym. Label Nature ${ }^{\mathrm{a}} \quad$ Ram. IR ${ }^{\mathrm{d}}$ PM3 $\quad$ AM1 MNDO

a

$\begin{array}{lll}1 \mathrm{a}^{\prime \prime} & \mathrm{v}_{24} & \gamma_{\mathrm{cc}} \\ 1 \mathrm{a}^{\prime} & \mathrm{V}_{1} & \delta_{\mathrm{CC}} \\ 2 \mathrm{a}^{\prime \prime} & \mathrm{v}_{25} & \gamma_{\mathrm{cc}} \\ 2 \mathrm{a}^{\prime \prime} & \mathrm{v}_{2} & \delta_{\mathrm{cc}} \\ 3 \mathrm{a}^{\prime \prime} & \mathrm{V}_{26} & \gamma_{\mathrm{ec}}+\gamma_{e a} \\ 4 \mathrm{a}^{\prime \prime} & \mathrm{V}_{27} & \left(\gamma_{\mathrm{cc}}+\gamma_{\mathrm{co}}\right) \\ & & \text { ring } \\ 5 \mathrm{a}^{\prime \prime} & \mathrm{v}_{28} & \gamma_{\mathrm{CH}}\end{array}$

$\begin{array}{lllll}\mathrm{E} & \mathrm{TD}^{\mathrm{e}} \mathrm{E} & \mathrm{TD}^{\mathrm{e}} \mathrm{E} & \mathrm{TD}^{\mathrm{e}}\end{array}$

$129 \quad-\quad \begin{array}{llllll}95 & 0.14 & 83 & 0.20 & 69 & 0.15\end{array}$

$215 \quad-\quad 207 \quad 0.17206 \quad 0.25 \quad 242 \quad 0.14$

$257 \quad-\quad 216 \quad 0.46221 \quad 0.53219 \quad 0.40$

$\begin{array}{llllllll}461 & 467 & 479 & 0.24 & 509 & 0.18 & 494 & 0.28\end{array}$

$\begin{array}{llllllll}478 & 483 & 505 & 0.09 & 512 & 0.22 & 497 & 0.37\end{array}$

$\begin{array}{llllllll}595 & 600 & 522 & 0.50 & 533 & 0.55 & 513 & 0.28\end{array}$

$\begin{array}{llllllll}652 & 659 & 672 & 0.10 & 678 & 0.07 & 684 & 0.13\end{array}$

$\begin{array}{lllllllllll}3 \mathrm{a} " & \mathrm{v}_{3} & \mathrm{~V}_{\mathrm{CC}}+\mathrm{V} & 717 & 724 & 695 & 0.22 & 727 & 0.25 & 692 & 0.44\end{array}$

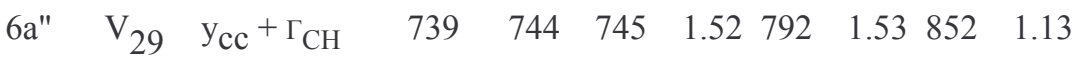

$\begin{array}{lllllllllll}7 \mathrm{a} " & \mathrm{~V}_{30} & \mathrm{~V}_{\mathrm{CH}} & 807 & 814 & 832 & 0.52 & 840 & 0.87 & 902 & 0.05\end{array}$

$\begin{array}{lllllllllll}4 \mathrm{a}^{\prime \prime} & \mathrm{V}_{4} & \mathrm{v}_{\mathrm{cc}} \text { ring } & 883 & 890 & 891 & 0.41 & 935 & 0.54 & 847 & 0.64\end{array}$

8a" $\quad \mathrm{V}_{3[} \quad \begin{array}{lllllllll}\Gamma_{\mathrm{CH}} & 903 & 910 & 901 & 0.30 & 887 & 0.20 & 947 & 0.54\end{array}$

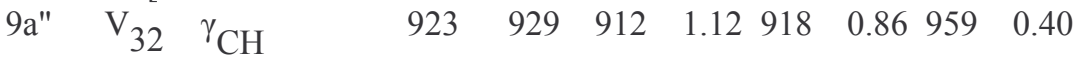

$\begin{array}{lllllllllll}5 \mathrm{a}^{\prime \prime} & \mathrm{v}_{5} & \gamma_{\mathrm{co}}+\Delta_{\mathrm{CH}} & 991 & 988 & 952 & 0.52 & 1012 & 0.30 & 998 & 0.56\end{array}$

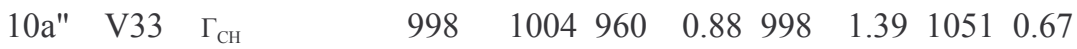

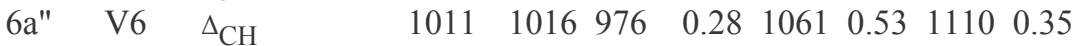

7a" $\quad \mathrm{V} 7 \quad \delta_{\mathrm{CH}} \quad \begin{array}{llllllllll}1025 & 1032 & 1041 & 0.28 & 1121 & 0.58 & 1143 & 0.25\end{array}$

$\begin{array}{lllllllllllll}8 \mathrm{a}^{\prime} & \mathrm{v}_{8} & \delta_{\mathrm{CH}} & 1078 & 1085 & 1077 & 0.41 & 1199 & 0.50 & 1206 & 0.25\end{array}$

9a' $\quad \mathrm{V}_{9} \quad \delta_{C H} \quad \begin{array}{lllllllll}1152 & 1158 & 1123 & 0.30 & 1242 & 0.36 & 1283 & 0.19\end{array}$

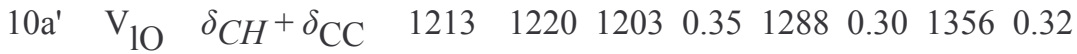

$\begin{array}{lllllllllll}11 \mathrm{a}^{\prime} & \mathrm{V}_{11} & \mathrm{Vcc}^{+} \mathrm{Vco} & 1253 & 1260 & 1300 & 0.83 & 1364 & 1.6 & 1409 & 1.10\end{array}$

$12 \mathrm{a}^{\prime} \quad \mathrm{V}_{12} \quad \delta_{\mathrm{CH}} \quad 1290 \quad 1296 \quad 1316 \quad 0.44 \quad 1393 \quad 0.60 \quad 1458 \quad 0.20$

$\begin{array}{llllllllllll}13 \mathrm{a}^{\prime} & \mathrm{V}_{13} & \mathrm{v}_{\mathrm{cc}} & 1385 & 1392 & 1390 & 0.98 & 1405 & 0.32 & 1503 & 1.6\end{array}$

$\begin{array}{lllllllllllllll}14 \mathrm{a}^{\prime} & \mathrm{V}_{14} & \mathrm{v}_{\mathrm{cc}} \text { ring } & & 1489 & 1496 & 1488 & 0.86 & 1506 & 0.84 & 1573 & 0.74\end{array}$

$\begin{array}{lllllllllllll}15 \mathrm{a}^{\prime} & \mathrm{V}_{15} & \mathrm{v}_{\mathrm{cc}} \text { ring } & 1574 & 1586 & 1612 & 0.75 & 1609 & 0.55 & 1586 & 0.19\end{array}$

$16 \mathrm{a}^{\prime} \quad \mathrm{V}_{16} \quad \mathrm{v}_{\mathrm{cc}} \quad \begin{array}{llllllllll}1638 & 1646 & 1672 & 0.40 & 1682 & 0.25 & 1639 & 1.30\end{array}$

$\begin{array}{llllllllllllll}17 \mathrm{a}^{\prime} & \mathrm{V}_{17} & \mathrm{v}_{\mathrm{cc}} & - & - & 1820 & 1791 & 1.29 & 1815 & 1.27 & 1750 & 0.95\end{array}$

$18 \mathrm{a}^{\prime} \quad \mathrm{V}_{18} \quad \mathrm{~V}_{\mathrm{CH}} \quad 3020 \quad 302630340.563105 \quad 0.43 \quad 33750.13$

$\begin{array}{lllllllllll}19 a^{\prime} & v_{19} & V_{\mathrm{CH}} & 3059 & 3064 & 3127 & 1.00 & 3170 & 0.79 & 3414 & 0.32\end{array}$

$\begin{array}{lllllllllll}20 a^{\prime} & V_{20} & V_{\mathrm{CH}} & 3101 & 3106 & 3136 & 0.81 & 3214 & 0.86 & 3441 & 0.25\end{array}$

$\begin{array}{lllllllllll}21 \mathrm{a}^{\prime} & \mathrm{V}_{21} & \mathrm{~V}_{\mathrm{CH}} & 3120 & 3124 & 3142 & 0.82 & 3309 & 1.29 & 3480 & 0.74\end{array}$

$\begin{array}{lllllllllll}22 \mathrm{a}^{\prime} & \mathrm{V}_{21} & \mathrm{~V}_{\mathrm{CH}} & 3129 & 3133 & 3163 & 0.77 & 3326 & 1.64 & 3492 & 0.62\end{array}$

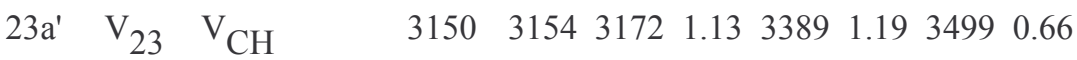

${ }^{a}$ Symmetry.

${ }^{b}$ Nature of the modes, $v$ : stretching vibration, $\delta$ : symmetric bending deformation, $y$ : out-of-plane bending deformation.

${ }^{c}$ Raman.

${ }^{d}$ FT-IR.

${ }^{e}$ IR transition dipole. 


\section{Acknowledgements}

The Patrimoine of the University of Liège, the Fonds National de la Recherche Scientifique and the Fonds de la Recherche Fondamentale Collective have supported this research. M.J.H.F. wishes to acknowledge the Fonds National de la Recherche Scientifique for position. AG is grateful to Dr. M. Ignatova for her translation of ref. 3 from Russian and also thanks Dr. I.C. Walker for fruitful discussions and critical reading of the manuscript during preparation. Professor A. Luxen is highly acknowledged for having allowed synthesis in the laboratories of University of Liège Cyclotron Research.

\section{References}

[1] M. Choura, N.M. Belgacem, A. Gandini, Macromolecules 29 (1996) 3839.

[2] A. Gandini, N.M. Belgacem, Progress. Polym. Sci. 22 (1997) 1203.

[3] R.G. Latypova, L.Y. Gubaidullin, U.M. Dzhemilev, N.M. Pozdeev, Zh. Strukt. Khim. 21 (1980) 197.

[4] A. Giuliani, M.-J. Hubin-Franskin, Int. J. Mass Spectrom. 205 (2001) 163.

[5] A. Giuliani, M.-J. Hubin-Franskin, Chem. Phys. Lett. 348 (2001) 3.

[6] A. Giuliani, J. Delwiche, S.V. Hoffmann, P. Limao-Vieira, N.J. Mason, M.-J. Hubin-Franskin, J. Chem. Phys. 119 (2003) 3670 .

[7] A. Giuliani, I.C. Walker, J. Delwiche, S.V. Hoffmann, P. Limao Vieira, NJ. Mason, B. Heyne, M. Hoebeke, M.-J. HubinFranskin, J. Chem. Phys. 119 (2003) in press.

[8] J. Fabian, T. Tchelitcheff, Bull. Soc. Chim. Fr. 453 (1947).

[9] U. Schmidt, J. Werner, Synthesis 12 (1986) 986.

[10] R.L. Brown, S.E. Stein, in: P.J. Linstrom, W.G. Mallard (Eds.), Boiling Point Data in NIST Chemistry WebBook, NIST Standard Reference Database Number 69, National Institute of Standards and Technology, Gaithersburg, MD, March 2003 (http://webbook.nist.gov)

[11] MOPAC 2000, J.J.P. Stewart, Fujitsu Limited, Tokyo, Japan, 1999.

[12] M.J.S. Dewar, W. Thiel, J. Am. Chem. Soc. 99 (1977) 4899.

[13] M.J.S. Dewar, E.G. Zoebisch, E.F. Healy, J.J.P. Stewart, J. Am. Chem. Soc. 107 (1985) 3902.

[14] J.J.P. Stewart, J. Comput. Chem. 10 (1989) 209.

[15] J.J.P. Stewart, J. Comput. Chem. 10 (1989) 221.

[16] J. Baker, J. Comput. Chem. 7 (1986) 385.

[17] W.J.E. Parr, R.E. Wasylishen, T. Schaefer, Can. J. Chem. 54 (1976) 3216.

[18] I.G. John, L. Radom, J. Am. Chem. Soc. 100 (1978) 3981. 